\title{
Laser Surface Annealing of Plasma Sprayed Coatings
}

\author{
Ahmed Ibrahim*, Yue Hung \\ Department of Mechanical Engineering Technology, Farmingdale State College, Farmingdale, USA. \\ Email: *Ahmed.ibrahim@farmingdale.edu
}

Received May $10^{\text {th }}, 2012$; revised June $13^{\text {th }}, 2012$; accepted June $20^{\text {th }}, 2012$

\begin{abstract}
Laser surface annealing provides a rapid and efficient means for surface alloying and modification of ceramic materials. In this study, Alumina-13\% Titania coatings were sprayed with a water-stabilized plasma spray gun. The coated surface was treated by Excimer laser having a wavelength of $248 \mathrm{~nm}$ and pulse duration of $24 \mathrm{~ns}$. The surface structure of the treated coating was examined by field emission scanning electron microscope and X-ray diffraction (XRD). A detailed analysis of the effects of various laser parameters including laser energy density (fluence), pulse repetition rate (PRR), and number of pulses on the morphology and the microstructure of the coatings are presented.
\end{abstract}

Keywords: Laser Annealing; Plasma Sprayed Coatings; SEM; Microstructure

\section{Introduction}

Plasma sprayed alumina-13\% titania (AT-13) coating is one of the most important coatings for many industrial applications [1-7]. They provide a dense and hard surface coating which are resistant to abrasion, corrosion, cavitation, oxidation and erosion and are therefore regularly used for wear resistance, electrical insulation, thermal barrier applications etc. A number of papers reported that the $\mathrm{Al}_{2} \mathrm{O}_{3}-\mathrm{TiO}_{2}$ coating containing $13 \mathrm{wt} \%$ of $\mathrm{TiO}_{2}$ showed the most excellent wear resistance among the AT-13 ones [3-5].

AT-13 coating is a typical ceramic coating with relatively high degree of porosity and the properties of these coatings, such as high temperature corrosion resistance, toughness and abrasive resistance, may thereby be reduced. To improve these properties, various methods have been proposed, such as impregnation with polymers or ceramics, seal sintering with liquid alloys and postlaser irradiation [8,11-21]. Laser surface treatment is one novel method that has potential for eliminating porosity and producing a homogeneous surface layer. Unfortunately, there is a very limited research on the effect of laser irradiation on the surface morphology and microstructural of AT-13 coatings. Previous research has shown that $\mathrm{CW}-\mathrm{CO}_{2}$ and $\mathrm{Nd}: Y A G$ lasers, with the appropriate parameters can improve the microstructural and morphological characteristics of AT-13 or Alumina coatings [13-15]. The formation of columnar grains was observed on the laser-treated zones. Chemical composition and thermal conductivity affected the way the materials

"Corresponding author. behaved during laser processing.

Excimer pulsed lasers are characterized by relatively short pulse duration ( $\sim 25 \mathrm{~ns}$ ), and wavelengths in the ultra-violet which result in very shallow treatment depths, of the order of a few hundred nanometers [15-17]. Pulsed laser irradiation can be used to melt or soften very thin surface layer of metal or ceramic that resolidifies, due to the high thermal gradients. Excimer lasers present certain distinct advantages for material processing applications in comparison to the other types of lasers. This is due to the fact that Excimer lasers operate in the ultraviolet region of the spectrum at wavelengths from $190 \mathrm{~nm}$ to 310 $\mathrm{nm}$. At these short wavelengths the reflectivity of most metals and ceramics is lower than at longer wavelengths and the absorptivity is higher [20].

In this investigation, Excimer laser was used for the surface annealing of free-standing AT-13 samples that were manufactured with a plasma spray gun. The effect of the Excimer laser annealing on the main features of the coated surface was evaluated in terms of surface modifications, microstructural and mechanical properties. A detailed parametric study was performed to investigate the effects of several parameters such as laser energy density (fluence), pulse repetition rate (PRR), number of pulses on the mechanical properties, surface morphology, and microstructure of the coatings.

\section{Experimental Materials and Procedures}

Free-standing AT-13 coatings were produced by a water-stabilized plasma (WSP) spray gun to obtain a thickness of $5 \mathrm{~mm}$; Table 1 lists the spray parameters. The 
coating was sprayed on mild steel substrates. The substrates were grit blasted and then a thin layer of aluminum was arc sprayed before spraying the AT-13 coating. The thin aluminum layer was dissolved using hydrochloric acid so that free-standing alumina-titania plates were obtained. All specimens were mechanically polished to a mirror surface in the present study, which results in a surface roughness of $0.7 \mu \mathrm{m}$ prior to laser treatment. This operation also facilitates the characterization of surface topological evolutions. The procedure consisted of successive grinding by silicon carbide papers and a final cloth polishing with a $0.25 \mu \mathrm{m}$ diamond particle suspension.

Excimer laser pulses was generated from a Lambda Physic Compex 205 system having Krypton Fluoride $(\mathrm{KrF})$ as the lasing gas, resulting in a laser wavelength of $248 \mathrm{~nm}$, a bandwidth of $300 \mathrm{pm}$ and a pulse duration of 24 ns. Table 2 lists the laser processing parameters employed in this study.

Surface morphology and microstructure of the coatings were investigated before and after laser treatment by optical microscopy (OM) and a LEO field emission scanning electron microscopy (SEM). Mitutoyo surface roughness and Vickers microhardness testers were used to measure the surface roughness and hardness of the treated and untreated surfaces. The Vickers hardness number (VHN) measurements were conducted under 300 gm load over 15 sec duel time.

Table 1. Spray parameters for water-stabilized plasma.

\begin{tabular}{cc}
\hline Parameter & Comment \\
\hline Particle size & $(40-80 \mu \mathrm{m})$ \\
WSP power & $125 \mathrm{KW}$ \\
Voltage & $300-320 \mathrm{~V}$ \\
Amperage & $400 \mathrm{~A}$ \\
Spray distance & $330 \mathrm{~mm}$ \\
Rotation speed & $90 \mathrm{rpm}$ \\
Feed rate & $34 \mathrm{~kg} / \mathrm{h}$ \\
\hline
\end{tabular}

Table 2. Laser processing parameters and surface properties of the coating.

\begin{tabular}{ccccc}
\hline Sample & $\begin{array}{c}\text { Pulse } \\
\text { Repetition }\end{array}$ & \# of Pulses & $\begin{array}{c}\text { Energy } \\
\text { Density }\end{array}$ & Hardness \\
\hline 1 & $(\mathrm{~Hz})$ & $(\mathrm{P})$ & $\left(\mathrm{mJ} / \mathrm{cm}^{2}\right)$ & $(\mathrm{HV})$ \\
2 & 50 & 1000 & 800 & 1897 \\
3 & 25 & 1000 & 800 & 1456 \\
4 & 10 & 1000 & 800 & 1504 \\
5 & 50 & 500 & 800 & 1740 \\
6 & 10 & 500 & 800 & 1620 \\
7 & 50 & 1000 & 400 & 1516 \\
8 & 50 & 2000 & 400 & 1240 \\
9 & 25 & 1000 & 400 & 1122 \\
10 & 50 & 500 & 400 & 1204 \\
\hline
\end{tabular}

The porosity of the coatings was estimated with quantitative image analysis on as polished and as laser treated samples. Five SEM images were analyzed using Image-J software from NIH (National Institute of Health, Bethes$\mathrm{da}, \mathrm{MD}, \mathrm{USA})$. The phase composition of the coatings before and after the laser treatment were determined by X-ray diffraction (XRD) using a Philips X-ray diffractometer (Philips APD 3520).

\section{Results and Discussion}

\subsection{Phase Composition}

The XRD profiles of the as-sprayed and laser treated coatings are illustrated in Figure 1. The analysis of the coatings indicated the presence of one distinct diffraction peak of the metastable $\gamma-\mathrm{Al}_{2} \mathrm{O}_{3}$ phase even though the starting powder was mainly $\alpha-\mathrm{Al}_{2} \mathrm{O}_{3}$ phase. This is consistent with what was observed in earlier studies on the plasma sprayed AT-13 coatings [3-7]. The formation of metastable phase is generally attributed to the large kinetic undercooling generated in the melt that favors nucleation of the metastable phase over the stable phase $\alpha-\mathrm{Al}_{2} \mathrm{O}_{3}$. The microstructure evolution during rapid solidification depends on the interplay between undercooling and solidification velocity [16]. The XRD profile of the laser treated surface matched well with that of the coating as shown in Figure 1. This result indicates that a very high cooling rate was achieved with the nano-second (ns) pulsed laser, which suppressed the transformation of $\gamma-\mathrm{Al}_{2} \mathrm{O}_{3}$ to $\alpha-\mathrm{Al}_{2} \mathrm{O}_{3}$.

\subsection{Microstructure of As-Sprayed Coatings}

Figure 2 shows the typical morphology of as-sprayed

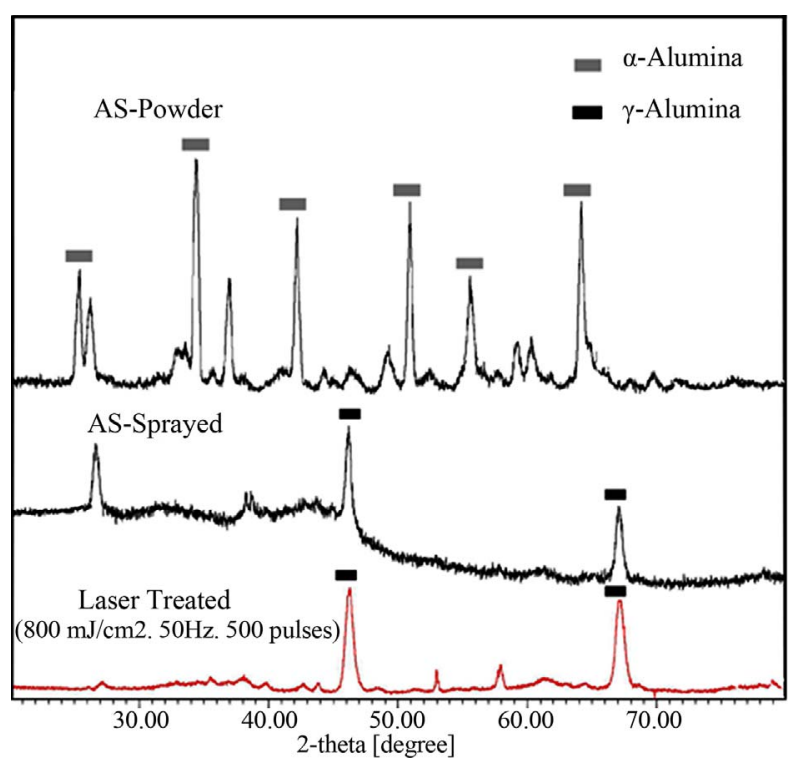

Figure 1. XRD of the as-sprayed and laser treated AT-13 coatings. 
and polished AT-13 coating. The microstructure is characterized by a high density of defects, e.g. inclusions and pores. The analysis of the SEM images of the cross sections of as-sprayed coatings revealed a number of features typical for thermally sprayed ceramics, i.e., structure lamination with lamellae aligned in the plane of the substrate and significant porosity formed predominantly in spaces between the contacting layers of the solidifying material, and a fine interlamellar crack network. The quality and performance of material produced by spraybased processing is significantly influenced by the porosity of the deposit. The presence of the porosity is generally detrimental, and it reduces the strength of the material, provides cracks initiation sites, and can result in the degradation of material properties, especially at high temperature.

\subsection{Effect of Laser Parameters on the Surface Morphology}

A parametric study was performed to investigate the effects of several parameters such as laser energy density (fluence), pulse repetition rate (PRR), and number of pulses on the surface morphology of the coatings. The laser processing parameters are presented in Table 2.

\subsubsection{Effect of Laser Energy Density (Fluence)}

Laser energy showed significant effect on the surface morphology of AT-13 coatings. Figures 3(a) and (b) show the surface morphologies of AT-13 coatings irradiated at two different fluences, $400 \mathrm{~mJ} / \mathrm{cm}^{2}$ and $800 \mathrm{~mJ} / \mathrm{cm}^{2}$. The chosen pulse repetition rates were $50 \mathrm{~Hz}$, and the number of pulses was 500 .

A laser fluence of $400 \mathrm{~mJ} / \mathrm{cm}^{2}$ was smaller than the threshold energy $\left(\sim 700 \mathrm{~mJ} / \mathrm{cm}^{2}\right)$ required for melting and recrystallization of the coating. However, this laser energy

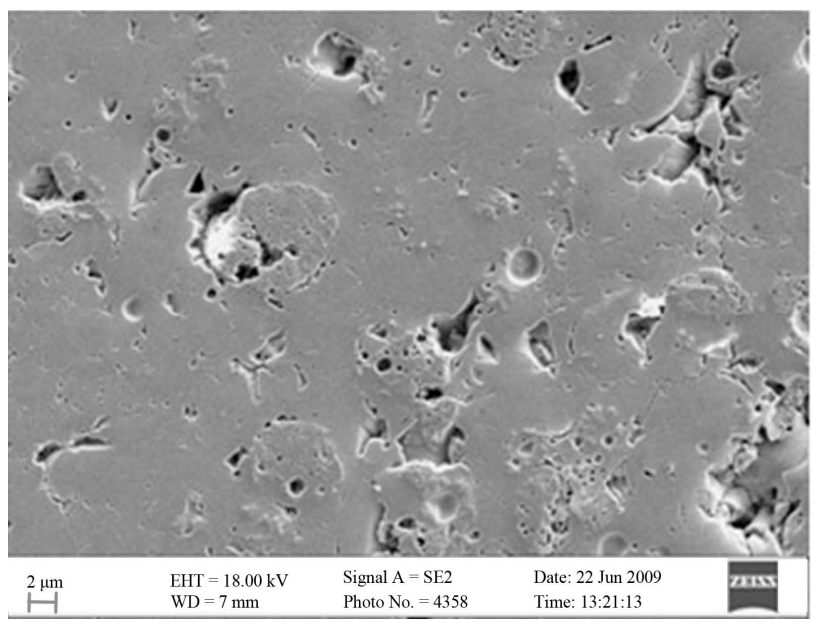

Figure 2. Morphology of as-polished $\mathrm{Al}_{2} \mathrm{O}_{3}+13 \% \mathrm{TiO}_{2}$ coating.

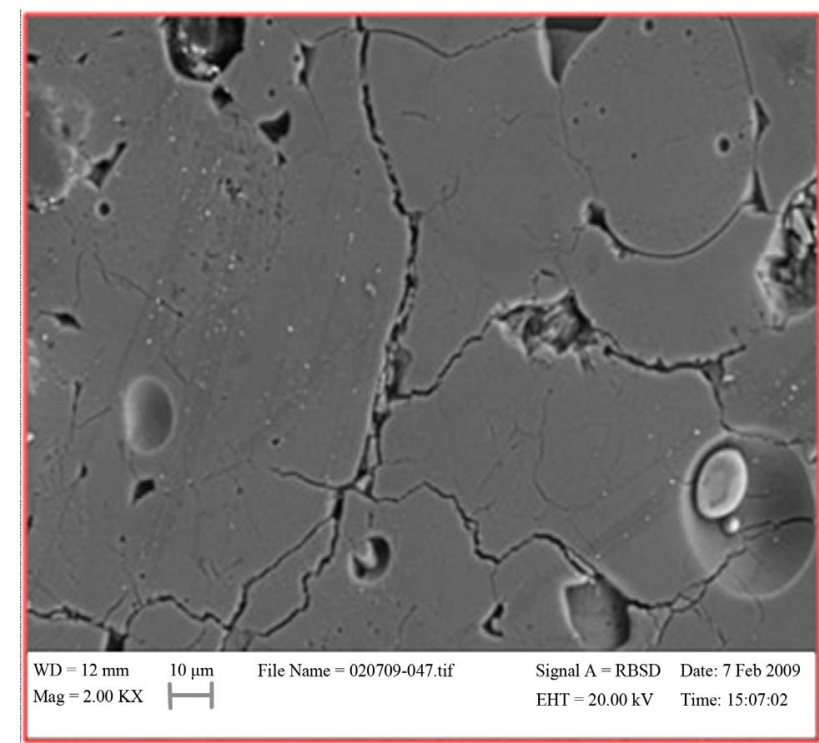

(a)

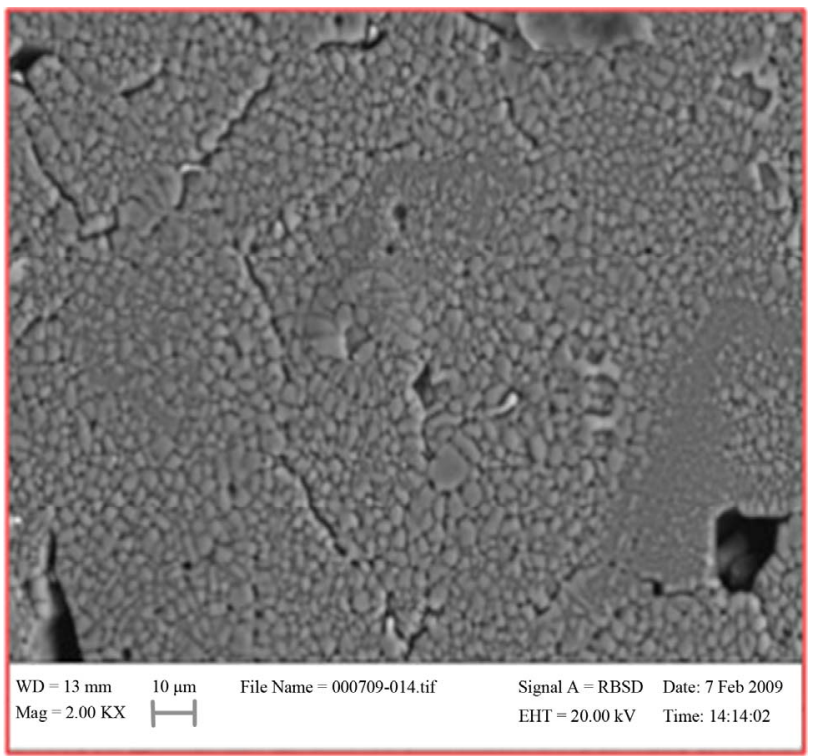

(b)

Figure 3. Effect of laser energy density on the surface morphology. (a) $400 \mathrm{~mJ} / \mathrm{cm}^{2}, 500$ shots, $50 \mathrm{~Hz}$; (b) $800 \mathrm{~mJ} / \mathrm{cm}^{2}$, 500 shots, $50 \mathrm{~Hz}$.

was sufficient to heat the surface and induce thermal stresses on the coating surface that led to the propagation of pre-existing cracks and the initiation of new cracks. As it was discussed in previous section, the microstructure of ceramic coating is characterized by a high density of defects, e.g. inclusions, pores, microcracks and macrocracks. Induced microcracks within splats are frequent, especially in the brittle ceramic coatings. Laser energy can easily induces microcracks or macrocracks in these types of microstructures. As clearly seen in Figure 3(b), when the laser energy density increased from 400 to $800 \mathrm{~mJ} / \mathrm{cm}^{2}$, the surface drastically changes to a denser 
microstructure. The irradiation at high laser density caused significant changes in the surface texture. First, the porosity significantly decreased (from $7.1 \%$ to $1.1 \%$ ) compared to the untreated coating. Second, the surface has been molten and re-solidified to form dense clusters and coherent dome-like columnar grains with a significant increase in surface hardness (from 1204 to $1740 \mathrm{Hv}$ ). The tendency of AT-13 coatings to form clusters of grains at higher fluence $\left(800 \mathrm{~mJ} / \mathrm{cm}^{2}\right)$, is the most pronounced feature of the surface morphology. It was one of the major findings of this study.

\subsubsection{Effect of Number of Laser Shots}

Effect of number of laser shots on the surface morphology and hardness of AT-13 coating has been examined.

When the number of laser pulses was increased at constant fluence and pulse repetition rates $\left(800 \mathrm{~mJ} / \mathrm{cm}^{2}\right.$, $50 \mathrm{~Hz}$ ) different surface morphologies were observed. As was mentioned in previous section, when the surface irradiated at fluence of $800 \mathrm{~mJ} / \mathrm{cm}^{2}$ with 500 shots, the surface drastically changes to clusters of grains. These grains grew vertically and form columnar grains shown in Figure 4(a).

When the number of laser shots increased to 1000 shots, tightly bonded clusters grains start to separate and flatten out as shown in Figure 4(b). The color of the surface layer changed to white-gray indicating change in surface chemistry or optical properties. However, the surface exhibits about $9 \%$ increase in microhardness compared to the surface treated with 500 shots. The porosity of the laser-treated layer with 1000 shots was higher than the one treated with 500 shots ( $1.1 \%$ to $1.5 \%)$.

\subsubsection{Effect of Pulse Repetition Rate (PRR)}

Figure 5 shows the surface morphologies of AT-13 coatings irradiated at fluence of $800 \mathrm{~mJ} / \mathrm{cm}^{2}$ with two different repetition rates 10 and $50 \mathrm{~Hz}$. The SEM image of the surface irradiated at lower pulse repetition rate $(10 \mathrm{~Hz})$ shows a very fine surface layer $(\sim 300 \mathrm{~nm})$ that was melted by the pulsed laser (Figure 5(a)). This melted layer exhibited smoother morphology with shine appearance and significantly different from the untreated surface. As clearly seen in Figure 5(a), laser pulses induced self-organized cluster cracks on this layer. These cluster cracks are very fine and more tightly woven together. These cluster cracks are the most pronounced features of the surface morphology irradiated at high energy and low pulse repetition rate. The porosity significantly decreased (from $7.1 \%$ to $2.2 \%$ ) compared to the untreated coating.

At higher pulse repetition rates $(50 \mathrm{~Hz})$, the surface drastically changes to a granular texture. The clusters of grains grew vertically and form columnar grains (Figure

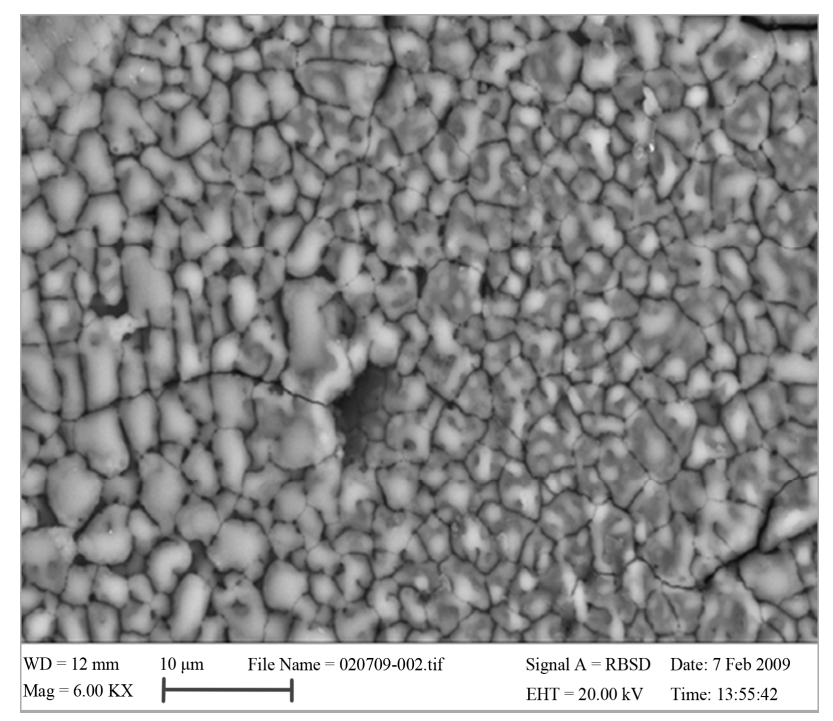

(a)

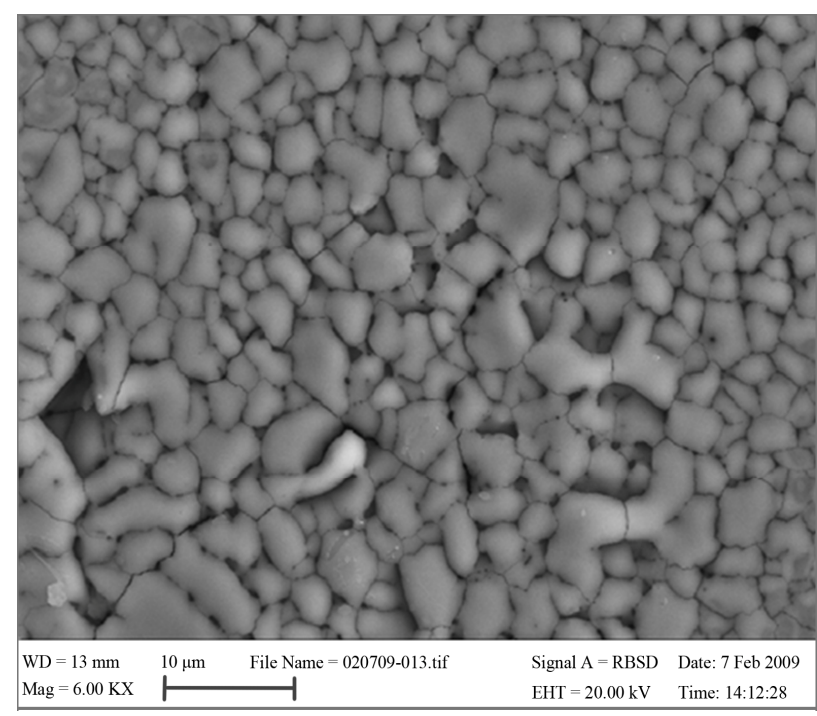

(b)

Figure 4. Effect of number of shots on the surface morphology. (a) 500 shots, $800 \mathrm{~mJ} / \mathrm{cm}^{2}, 50 \mathrm{~Hz}$; (b) 1000 shots, 800 $\mathrm{mJ} / \mathrm{cm}^{2}, 50 \mathrm{~Hz}$.

5(b)). As mentioned in previous section, this surface morphology exhibited much higher hardness than the one irradiated at $10 \mathrm{~Hz}$. The porosity of the laser treated layers was greatly reduced (from $7.1 \%$ to $1.1 \%$ ) compared to the untreated coating. This effect is attributed to the heat accumulation in the sample at higher pulse repetition rate.

These results strongly suggest that the pulse repetition rate has a significant effect on the surface morphology of AT-13 coatings.

\subsection{Microstructure of the Laser Treated Layers}

The use of pulsed Excimer lasers in surface processing of 
materials relies on understanding the nature of the interaction between the laser energy and the material. The short wavelength, (200 - $400 \mathrm{~nm}$ depending on the laser gas) and the short pulse duration (24 ns) mean that for most materials, the energy is absorbed in a region of the surface that is shallow $(10 \mathrm{~nm})$ relative to the thermal diffusion length $(100 \mathrm{~nm})$ in the material $[15,20]$.

Figure 5(b) shows the coating layer treated at $(800$ $\mathrm{mJ} / \mathrm{cm}^{2}, 50 \mathrm{~Hz}, 500 \mathrm{P}$ ). This layer consists of fully dense microstructure differing significantly from the surface of untreated coating. Increasing both laser energy density (fluence) and the pulse repetition rate (PRR) have significant thermal effect on the treated layer. The surface of the treated layer shows dome-shaped surface morphology due to the rounded crystal edges. The layer structure is homogeneous and the columnar grain-like structure extends from the bottom to the top of the laser treated layer.

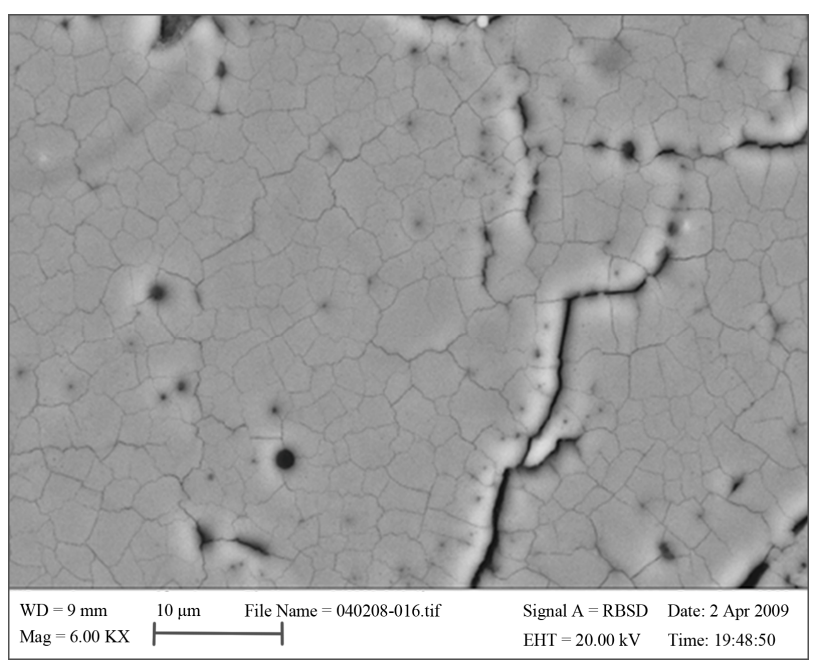

(a)

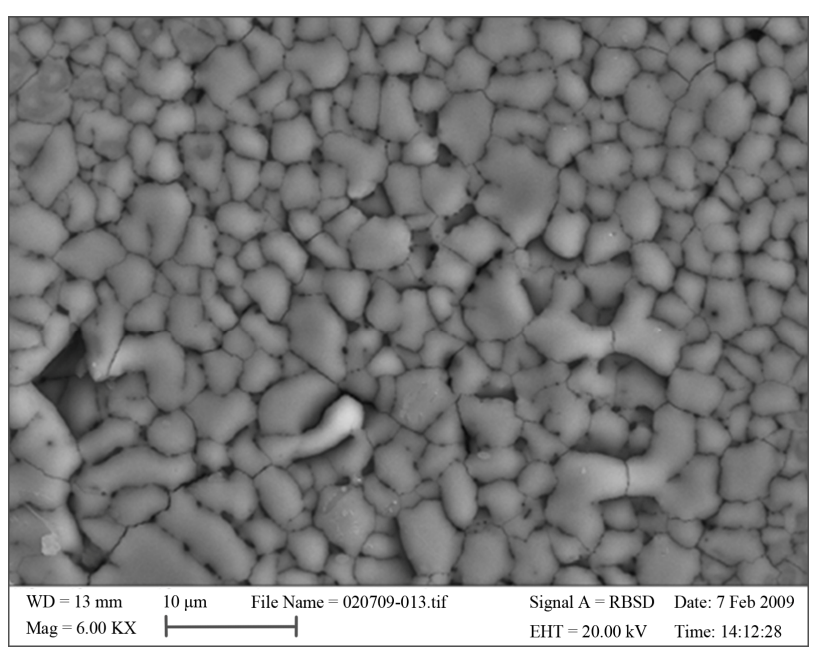

(b)

Figure 5. Effect of pulse repetition on the surface morphology. (a) $10 \mathrm{~Hz}, 500$ shots, $800 \mathrm{~mJ} / \mathrm{cm}^{2}$; (b) $50 \mathrm{~Hz}, 500$ shots, $800 \mathrm{~mJ} / \mathrm{cm}^{2}$.

\subsection{Mechanical Properties (Hardness)}

Figure 6 shows the Microhardness values of the surface of laser treated and untreated AT-13 coatings. Coatings irradiated at $\left(800 \mathrm{~mJ} / \mathrm{cm}^{2}, 50 \mathrm{~Hz}, 1000 \mathrm{P}\right)$ showed a maximum hardness of $1897 \mathrm{HV}$, corresponding to a hardness increase of $66 \%$ compared with the untreated coatings. While coatings irradiated with $\left(400 \mathrm{~mJ} / \mathrm{cm}^{2}, 50 \mathrm{~Hz}\right.$, $1000 \mathrm{P}$ ) showed a $32 \%$ increase of hardness compared with untreated coatings. These results suggest that the laser energy density (fluence) plays a major role in modifying the surface hardness of the coating.

When the laser energy density increased from 400 to $800 \mathrm{~mJ} / \mathrm{cm}^{2}$, the surface drastically changes to a much denser microstructure as shown in Figure 5(b). The irradiation at high laser density caused significant changes in the surface texture. The surface has been molten and resolidified to form dense clusters and coherent dome-like columnar grains with a significant increase in surface hardness. Increasing the number of laser shots from 500 to 1000 at laser energy of $800 \mathrm{~mJ} / \mathrm{cm}^{2}$ resulted in small increase $(\sim 9 \%)$ in the surface hardness whereas an increase of $26 \%$ obtained for the laser energy of 400 $\mathrm{mJ} / \mathrm{cm}^{2}$ for the same laser parameters. It is important to point out that the pulse repetition rate has a similar effect on the hardness as the laser energy. At higher pulse repetition rates $(50 \mathrm{~Hz})$ the surface exhibited a higher hardness than the one irradiated at $10 \mathrm{~Hz}$. A fluence of 200 $\mathrm{mJ} / \mathrm{cm}^{2}$ was much lower than the threshold energy density required for melting and recrystallization of the coating and only shows a slight change in the hardness of the coating.

\section{Conclusions}

The following conclusions can be drawn from this investigation:

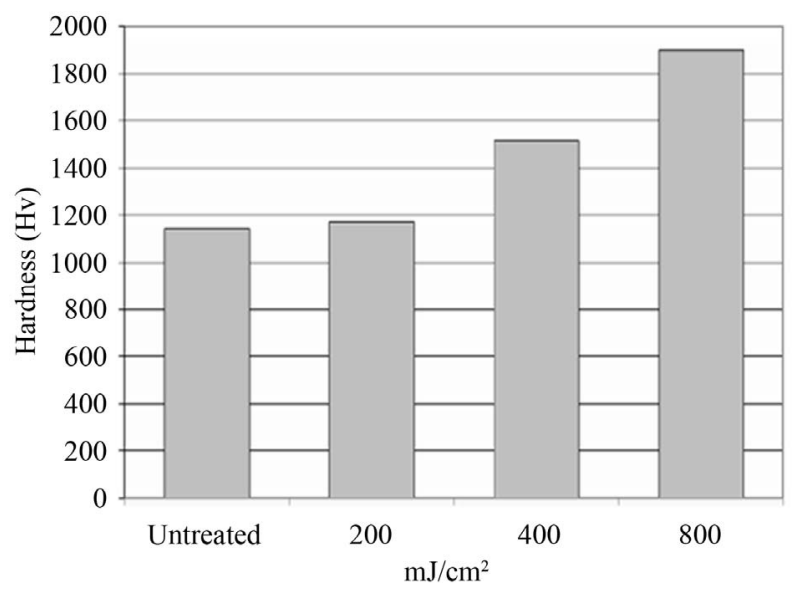

Figure 6. Microhardness values for the laser treated and untreated coatings. 
Different surface modifications take place during Excimer laser irradiation of plasma sprayed AT-13 coating, depending essentially on the laser energy density (fluence) and the pulse repetition rate (PRR). The AT-13 surface irradiated at $\left(800 \mathrm{~mJ} / \mathrm{cm}^{2}, 50 \mathrm{~Hz}, 500 \mathrm{P}\right)$ composed of fully dense microstructure differing significantly from the surface treated at lower laser energy density and pulse repetition rate (PRR). Increasing both PRR and laser density have a significant thermal effect on the treated layer.

The surface of the laser treated layer exhibits domeshaped surface morphology. The microhardness of this modified layer was significantly increased compared to the as sprayed coating. Moreover, the porosity of the laser treated layers was significantly decreased. SEM and XRD observations demonstrated that the microstructure of the laser treated surface is composed of mainly of nanometer-sized $\gamma-\mathrm{Al}_{2} \mathrm{O}_{3}$. Therefore, the intense and extremely short pulse of the Excimer laser resulted in grain refinement and microstructural modification of the plasma sprayed alumina-titania.

\section{REFERENCES}

[1] L. Pawlowski, "The Science and Engineering of Thermal Spray Coatings," Wiley, New York, 1995.

[2] R. McPherson, "A Review of Microstructure and Properties of PS Ceramic Coatings," Surface and Coatings Technology, Vol. 39/40, 1989, pp. 173-180. doi:10.1016/0257-8972(89)90052-2

[3] D. Goberma, L. Shaw, E. Jordan and M. Gell, "Microstructure Development of $\mathrm{Al}_{2} \mathrm{O}_{3}-13 \mathrm{wt} \% \mathrm{TiO}_{2}$ Plasma Sprayed Coatings Derived from Nanocrystalline Powders," Acta Materialia, Vol. 50, No. 5, 2002, pp. 1141-1152. doi:10.1016/S1359-6454(01)00414-1

[4] E. H. Jordan, M. Gell, Y. H. Sohn, D. Goberman, L. Shaw, S. Jiang, M. Wang, T. D. Xiao, Y. Wang and Y. P. Strutt, "Fabrication and Evaluation of Plasma Sprayed Nanostructured Alumina-Titania Coatings with Superior Properties," Materials Science and Engineering A, Vol. 301, No. 1, 2001, pp. 80-89. doi:10.1016/S0921-5093(00)01382-4

[5] A. Ibrahim, H. Salem and C. Berndt, "Characterization of Nanostructured and Conventional Alumina-13wt\% Titania Coatings," International Thermal Spray Conference, Maastricht, 2-4 June 2008.

[6] M. Gell, E. H. Jordan, Y. H. Sohn, D. Goberman, L. Shaw and T. D. Xiao, "Development and Implemenation of Plasma Sprayed Nanostructured Ceramic Coatings," Surface and Coatings Technology, Vol. 146-147, 2001, pp. 48-54. doi:10.1016/S0257-8972(01)01470-0

[7] W. Meidong and L. Shaw, "Effects of the Powder Manufacturing Method on Microstructure and Wear Performance of Plasma Sprayed Alumina-Titania Coatings," Surface \& Coatings Technology, Vol. 202, No. 1, 2007, pp. 34-44. doi:10.1016/j.surfcoat.2007.04.057

[8] J. R. Davis, "Handbook of Thermal Spray Technology,"
ASM International, 2004.

[9] R. S. Lima, A. Kucuk, U. Senturk and C. C. Berndt, "Evaluation of Microhardness and Elastic Modulus of Thermally Sprayed Nanostructured Zirconia Coatings," Journal of Thermal Spray Technology, Vol. 135, No. 1, 2001, pp. 179-180.

[10] E. H. Jordan, M. Gell, Y. H. Sohn, D. Goberman, L. Shaw, S. Jiang, et al., "Fabrication and Evaluation of Plasma Sprayed Nanostructured Alumina-Titania Coatings with superior Properties," Materials Science and Engineering: A, Vol. 301, No. 1, 2001, pp. 80-89. doi:10.1016/S0921-5093(00)01382-4

[11] R. S. Lima, A. Kucuk and C. C. Berndt, "Bimodal Distribution of Mechanical Properties on Plasma Sprayed Nanostructured Partially Stabilized Zirconia," Materials Science and Engineering: A, Vol. 327, No. 2, 1997, pp. 224-232.

[12] G. Antou, G. Coddet and F. Machi, "Modification of Ceramic Thermal Spray Deposit Microstructures Implementing in Situ Laser Remelting," Surface and Coatings Technology, Vol. 172, No. 2-3, 2003, pp. 279-290. doi:10.1016/S0257-8972(03)00431-6

[13] J. Iwaszko, "Surface Remelting Treatment of PlasmaSprayed $\mathrm{Al}_{2} \mathrm{O}_{3}+13 \mathrm{wt} \% \mathrm{TiO}_{2}$ Coatings," Surface \& Coatings Technology, Vol. 201, No. 6, 2006, pp. 3443-3451. doi:10.1016/S0257-8972(03)00431-6

[14] L. Bradley, L. Li and F. H. Stott, "Characteristics of the Microstructures of Alumina-Based Refractory Materials Treated with $\mathrm{CO}_{2}$ and Diode Lasers," Applied Surface Science, Vol. 138-139, 1999, pp. 233-239.

[15] J. Brannon, "Excimer Laser Ablation and Etching," America Vacuum Society, New York, 1993.

[16] M. J. Aziz, "Nonequilibrium Interface Kinetics during Rapid Solidification," Materials Science and Engineering: $A$, Vol. 178, No. 1-2, 1994, pp. 167-170. doi:10.1016/0921-5093(94)90537-1

[17] E. Hontzopoulos and E. Damigos, "Excimer Laser Surface Treatment of Bulk Ceramics," Applied Physics A: Materials Science \& Processing, Vol. 52, No. 6, 1991, pp. 421-424. doi: $10.1007 / \mathrm{BF} 00323653$

[18] C.-K. Lin, C. C. Berndt, S.-H. Leigh and K. Murakami, "Acoustic Emission Studies of Alumina-13\% Titania FreeStanding Forms during Four-Point Bend Tests," Journal of the American Ceramic Society, Vol. 80, No. 9, 1997, pp. 2382-2394. doi:10.1111/j.1151-2916.1997.tb03130.x

[19] A. Kucuk, R. S. Lima and C. C. Berndt, "Influence of Plasma Spray Parameters on Spray Efficiency of Yttria Partially Stabilized Zirconia Coatings II: Physical Characteristics," The American Ceramic Society, Submitted, 2000.

[20] T. R. Jervis, M. Nastasi and J. P. Hirvonen, "Advances in Excimer Laser Surface Processing of Materials," IEEE/ LEOS Summer Topical Meetings, Keystone, 5-9 August 1996.

[21] H. Li, S. Costil, V. Barnier and C. Coddet, "Surface Modifications Induced by Nanosecond Pulsed Laser Irradiation of Metallic Substrates," Surface \& Coatings Technology, Vol. 201, No. 3-4, 2006, pp. 1383-1392. doi:10.1016/j.surfcoat.2006.02.012 